\title{
Personal and Family Resources Related to Depressive and Anxiety Symptoms in Women during Puerperium
}

\author{
David Feligreras-Alcalá, Antonio Frías-Osuna * and Rafael del-Pino-Casado® \\ Department of Nursing, Faculty of Health Sciences, University of Jaén, 23071 Jaén, Spain; \\ dfa00001@red.ujaen.es (D.F.-A.); rdelpino@ujaen.es (R.d.-P.-C.) \\ * Correspondence: afrias@ujaen.es; Tel.: (+34)-953-212574
}

Received: 10 June 2020; Accepted: 18 July 2020; Published: 20 July 2020

check for updates

\begin{abstract}
Introduction: This study investigated the relationship between personal and family resources (i.e., social support, family functioning, self-efficacy in care, sense of coherence and perceived burden of care) and depressive and anxiety symptoms in women during the puerperium, adjusting for stressors. Methods: This is a quantitative research design, carried out through a descriptive, cross-sectional correlation study. This study includes 212 women over the age of 19 who gave birth from March to September 2019 in Maternal and Child Hospital of Jaén (Spain). Women were selected during the immediate postpartum period. The variables analysed were postpartum depressive symptoms (Edinburgh scale), anxiety symptoms (STAI state anxiety questionnaire), perceived social support (Duke-UNC-11), family functioning (family APGAR), self-efficacy in care (Lawton), sense of coherence (SOC-13), perceived burden (Caregiver Strain Index) and stressful life events (Holmes and Rahe). The main analysis consisted of a multiple linear regression. Results: The regression model of depressive symptoms found a positive association with perceived burden $(\beta=0.230, p=0.015)$ and negative associations with self-efficacy in care $(\beta=-0.348, p<0.001)$, social support $(\beta=-0.161, p<0.001)$ and sense of coherence $(\beta=-0.081, p=0.001)$. The regression model of anxiety symptoms obtained a positive association with perceived burden $(\beta=1.052, p<0.001)$ and negative associations with self-efficacy in care $(\beta=-0.329, p=0.041)$, social support $(\beta=-0.234, p=0.001)$ and sense of coherence $(\beta=-0.262, p<0.001)$. Discussion: Firstly, depressive and anxiety symptoms in the puerperium period may be more prevalent than in other periods of a woman's life. Secondly, perceived social support, self-efficacy in caring for the newborn and sense of coherence may be protective factors for depressive and anxiety symptoms in the puerperium period. Finally, perceived burden in caring for the newborn may be a risk factor for these symptoms.
\end{abstract}

Keywords: depression; postpartum; anxiety; risk factors; puerperium; pregnancy

\section{Introduction}

The postpartum or puerperium period is defined as the period of 6-8 weeks beginning $1 \mathrm{~h}$ after the birth of the foetus and the expulsion of the placenta, and it reflects the approximate time needed for uterine involution and return of most maternal organic systems to their pre-pregnancy state; it is also characterised by psychosocial adaptations, including changes in parental role [1,2], modifications in family relationships [3] and alterations in self-perception and body image [4]. It represents a period of special vulnerability for women in the appearance of different psychological disorders, especially depressive symptoms [1] and anxiety [5].

Depression is a mental disorder that constitutes the main cause of disability in the world and contributes significantly to the overall global burden of morbidity [6]. The lifetime rate of depression is around $20 \%$ of the population, affecting more women than men [7]. Puerperal depression is not recognised as a separate diagnosis of depression in the Diagnostic and Statistical Manual of Mental 
Disorders (DSM). However, in its fifth edition (DSM-V), it includes as a novelty compared to its previous version, a major depressive disorder with onset in the peripartum, considering its development during pregnancy or in the first four weeks of postpartum [8]. The World Health Organization (WHO), in its 11th Revision of International Statistical Classification of Diseases and Related Health Problems, defines puerperal depression as a mild mental and behavioural disorder that begins in the 6 weeks of postpartum [6].

Depressive disorders during the postpartum period can be classified into three categories: postpartum sadness, postpartum psychosis and postpartum depression. Postpartum sadness affects $50-85 \%$ of women, appearing around the 4 th day and disappearing on the 10th postpartum day, with symptoms such as short periods of crying, anxiety, sadness, difficulty sleeping, confusion and irritability. Postpartum psychosis has a prevalence of $0.1-0.2 \%$, occurring in the first 2 weeks postpartum. It includes symptoms such as agitation, paranoia, disorganised thinking and hallucinations. It requires emergency treatment for risk of suicide or harm to the newborn $[9,10]$.

Postpartum or puerperal depression has a prevalence of $12-13 \%$ at 6 weeks of postpartum in industrialised countries [1,11], as well as a prevalence period of $19 \%$ in the first 12 months of postpartum [12]. In Spain, the studies carried out place it between $10 \%$ and $13 \%[13,14]$. The usual clinical manifestations are depressive mood, irritability, loss of interest in habitual activities, insomnia, fatigue and loss of appetite [10]. The consequences of depressive symptoms during puerperium stage not only affect the social and occupational functioning of women but also extend to the couple, the family and mother-child interaction [15]. Puerperal depression is associated with a worse quality of life for the newborn, which may affect their emotional, intellectual and cognitive development [16,17].

The prevalence of puerperal depression can be determined through questionnaires, used as a screening method for depressive symptoms in this period, or through a structured clinical interview, which determines the diagnosis of major or minor depressive disorders [9]. The prevalence of a major depressive episode diagnosed through clinical interview is lower than the prevalence established through screening [18].

Anxiety is a common disorder in women, since $30 \%$ of them experience at least one episode throughout their lives [7]. During the puerperium, prevalence of anxiety is $13-18 \%[19,20]$, and the combined presence of both disorders, anxiety and depression is estimated at $13 \%$ [20]. The presence of anxiety in puerperium is related to different adverse outcomes, such as a decreased effectiveness of the parental role, difficulty in coping or lower levels of confidence [21-23].

Despite negative consequences of the presence of depressive symptoms or anxiety on women's health in the postpartum period, this is a neglected aspect by the health services, as well as the object of few interventions in prevention and promotion of health [24]. These interventions inevitably go through identification of risk factors of both processes.

Traditionally, literature has studied different factors associated with the appearance of depressive symptoms or anxiety in the postpartum period, which could be divided based on different areas of women: physical or biological factors, such as delicate physical health [25]; psychological factors, such as depression or anxiety during pregnancy [26]; previous psychiatric illness [26] or a poor relationship with her couple [13]; obstetric factors, such as unwanted pregnancy [27]; paediatric factors, such as initiation or not of breastfeeding [28]; or socio-demographic factors, such as maternal age [29] or low economic status [26].

In addition, the consequences of the presence of anxiety and postpartum depression on emotional regulation, the formation of the attachment system and the development of the child are currently gaining importance; several studies show that the presence of anxiety and postpartum depression is associated with a lower performance of infant language, as well lower social engagement, less mature regulatory behaviours and more negative emotionally, and higher cortisol reactivity [30,31]. In this sense, in the systematic review carried out by Warfa et al. the presence of insecure attachment appears as an important risk factor in the development of postpartum depression, as well as its relationship with other factors such as low social support or a lower level of family functioning [32]. Likewise, there 
are also factors associated with the presence of depressive symptoms or anxiety in the postpartum period that have been studied to a lesser extent than those described above and that we could include in a personal and family resources model. Among these factors, the authors find social support (i.e., instrumental, emotional or informational support provided by family and friends) [33], family functioning (i.e., perception of the level of fulfilment of basic family functions) [34], self-efficacy (i.e., belief of efficacy) in care [35], sense of coherence [36] and perception of the burden of care [37]. Sense of coherence is defined as a global orientation that expresses the degree of confidence that the stimuli that come from internal and external environments of oneself in the course of life are structured, those are predictable and explainable, that resources are available to meet the demands represented by these stimuli and these demands are challenges, worthy of investment and commitment [36]. Perceived burden is defined as the caregiver's assessment that the care situation is beyond their ability to cope with adequately [37].

Although previous personal and family resources have been related to emotional health in other areas of family care $[38,39]$, their study in puerperium has been scarce and inconclusive with only a few studies that analyse issues related to personal and family resources [40-48]. Therefore, further research is needed on this issue.

With the development of this research, the authors have proposed the following objectives: (1) to determine point prevalence of depressive symptoms and anxiety in women at 6 weeks after delivery; (2) to establish the possible relationship between personal and family resources (i.e., perceived social support, family functioning, self-efficacy in care, sense of coherence and perceived burden) and depressive symptoms and anxiety in women in puerperium; and (3) to identify a possible risk profile for the development of postpartum depression and anxiety in women during puerperium.

\section{Methods}

\subsection{Design}

A quantitative research was carried out through a descriptive, cross-sectional design of correlation in women during puerperium and located in the province of Jaén, Spain.

\subsection{Ethical Considerations}

This study was approved by the Research Ethics Committee of Jaén (Public Health System of Andalusia). This study was carried out in accordance with state legislation and the principles established in the Helsinki Declaration of 1964. Informed Consent was requested as a guarantee of respect for bioethical principle of autonomy. The confidentiality and privacy of data obtained was guaranteed. Participants were given the opportunity, both verbally and in writing, to refuse to participate or leave the study at any time.

\subsection{Participants}

The participants in this study were women who gave birth at Maternal and Child Hospital of Jaén between March and September 2019. After an exhaustive review of literature, the authors determined to carry out a systematic random sampling. The sample size was calculated using Epidat 3.1 program, assuming a significance level of $5 \%$ and a power of $80 \%$, in which 200 sample units are necessary to detect a correlation coefficient of at least 0.175 [49]. This sample size was increased by $10 \%$ to prevent future non-responses. Considering the number of births estimated at Maternal and Child Hospital of Jaén during the study period, in addition to the necessary sample of 220 women, a sampling fraction of five was established. The first sample was selected by lottery method with simple random sampling. Every following sample was selected from the Hospital's birth register until the desired sample size was obtained. The exclusion criteria were the following: (1) equal age or less than 19 years, (2) previous history or current staff of psychiatric pathology, (3) serious illness or exitus of the newborn, (4) not 
understanding the Spanish language, (5) not accepting participation in the study or (6) not signing the informed consent.

\subsection{Study Measures}

\subsubsection{Sociodemographic Variables}

Some of the variables collected were marital status, educational level, employment status, family income, pregnancy search and family history of psychiatric pathology.

\subsubsection{Independent Variables}

The independent variables of this study are the perceived social support, perception of family functioning, self-efficacy in newborn's care, sense of coherence and perceived burden.

Perceived social support was measured by the Duke-UNC-11 questionnaire [33], a self-administered instrument that measures social support both in its affective dimension (i.e., referring to expressions of love, appreciation, sympathy or belonging) and its confidential dimension (i.e., that through which people can receive information, advice or guidance). It consists of 11 items along with a 5-point, Likert response scale, ranging from 1 (Much less than I want) to 5 (As much as I want). Scoring for total questionnaire ranges from 11 to 55 points (directly proportional to the level of perceived social support). This questionnaire has been validated in the Spanish population with adequate clinimetric properties (e.g., Cronbach's alpha coefficient of 0.93) [50]. In this study, Cronbach's alpha coefficient was 0.91 .

The perception of family functioning was assessed using the family APGAR questionnaire [34], which is a self-administered questionnaire that shows how a person perceives the level of functioning of a family unit. It consists of five questions, each of which can take one of the following scores: 0 (Almost never), 1 (Sometimes), 2 (Almost always). The range of scores is between 0 and 10 points. This questionnaire is validated in the Spanish population, presenting a Cronbach alpha coefficient of 0.84 [51]. In our study, Cronbach's alpha coefficient was 0.85 .

Self-efficacy in newborn care was measured by the mastery or self-efficacy dimension of Lawton's questionnaire [35]. This is a self-administered questionnaire that includes 12 items with a Likert response scale, ranging from 1 (totally disagree) to 5 (totally agree), where higher scores indicate greater self-efficacy in care. The items on this scale were adapted for newborn care in this study. In this study, Cronbach's alpha coefficient was 0.77.

The sense of coherence was collected using the SOC-13 Sense of Coherence scale [36]. This scale assesses three dimensions of sense of coherence: compressibility, manageability and significance, which are closely related. It consists of 13 items that are answered on a Likert scale with seven scores, ranging from 1 (always) to 7 (never), where a higher score indicates a greater sense of coherence. This scale is validated in the Spanish population, presenting a Cronbach's alpha of 0.80 [52]. In this study, Cronbach's alpha coefficient was 0.88 .

Perceived burden was assessed using the Caregiver Strain Index [53], a scale that measures the degree of overexertion of carers of dependent people in general. It consists of 13 items with a true or false dichotomous response. Each affirmative answer scores 1, so the range of scores goes from 0 to 13 (directly proportional to burden). This instrument was validated in the Spanish caregiver population [54], with a Cronbach's alpha of 0.80 . The items of this scale were adapted for newborn's care in the performance of this study. In this study, Cronbach's alpha coefficient was 0.71.

\subsubsection{Dependent Variables}

Dependent symptoms and anxiety in puerperium were included as dependent variables.

Depressive symptoms were measured using the Edinburgh postpartum depression scale [55]. This scale is used to detect depressive states in the postpartum period. It is a self-administered scale of 10 items, with four possible response alternatives, scored from 0 to 3, depending on the severity of 
symptoms. Scores range from 0 to 30 points (proportional to level of depressive symptoms). A cut-off point, equal to or greater than 10 points, is considered adequate to detect depressive symptoms in this period, with a sensitivity of $79 \%$, a specificity of $95 \%$ and a positive predictive value of $63 \%$ [14]. Its use is recommended in the first 6 weeks of postpartum to ensure correct screening for depressive symptoms in puerperium, according to the Ministry of Health, Social Services and Equality of Spain [56]. It is validated and widely applied in Spain [14]. In this study, Cronbach's alpha coefficient was 0.86.

Anxiety was measured by STAI state-trait's anxiety questionnaire [57], a self-administered instrument that measures two independent concepts of anxiety: on the one hand, anxiety as a state is referred to as a transient emotional condition; on the other hand, anxiety as a trait is described as a relatively stable anxious propensity. In the development of this research, anxiety-status was evaluated as a specific measure of anxiety during this study period. This subscale consists of 20 items, with 4-point, Likert responses (proportional to intensity of anxiety). Total subscale scores range from 0 to 60 points, with the 75th percentile recommended as a cut-off point in adult women [57]. This questionnaire is validated in the Spanish population, presenting a Cronbach's alpha coefficient of 0.94 [58]. In this study, the Cronbach's alpha coefficient of the state subscale was 0.94 .

\subsubsection{Control Variable}

The presence of stressful life events was included as a control variable, and these were measured using the Holmes-Rahe social readjustment scale [59]. It consists of 43 vital events to which a score is assigned according to the stress it generates in the person. Stressful events experienced in the last year are selected and previously established scores are added. This scale was adapted to the Spanish population [60].

\subsection{Data Collection Procedure}

Women were captured during their hospital admission after childbirth, in the period between 15 March 2019 and 15 September 2019. The study was explained to those selected women and they were offered to participate in the study. Each woman who agreed to participate was given the Informed Consent model for reading and signing and corresponding questionnaires. These questionnaires were self-filled anonymously during the 6 th week after the delivery. There was a total of eight non-responses (3.64\%), so a definitive sample was 212 women.

\subsection{Data Analysis}

A descriptive analysis of the quantitative variables was carried out through measures of central tendency (i.e., means or medians) and dispersion measures (i.e., standard deviations or interquartile range), in addition to the frequencies and percentages of the qualitative variables. A correlation matrix was performed to explore the relationships between the variables, and the Pearson's correlation coefficient $(r)$ and the Spearman's Rho coefficient were used (in those variables that did not meet the normality assumptions). For the multivariable analysis, a multiple linear regression (stepwise method) was carried out, with prior confirmation of assumptions of the linear regression model: normality (Kolmogorov-Smirnov test); linearity (seen with partial regression graphs); homoscedasticity (graph of standardised residue); error independence (Durbin-Watson); non-collinearity (variance inflation factor and tolerance). Those variables that did not meet normality were transformed by Box-Cox transformations, with the help of Statistica 8.0 (Stat Soft Inc., Tulsa, USA) program [61]. For the correlations and multivariable analyses, the level of statistical significance was set at 0.05 . Relationships between the proposed variables were examined with the help of the SPSS v22.0 (IBM International Business Machines Corporation, Armonk, NY, USA) program. 


\section{Results}

\subsection{Description of Sample and Study Variables. Prevalence of Depression and Anxiety}

Descriptive data of the sample and study variables are shown in Table 1. Out of the total of 220 postnatal women sampled, 212 participated in the study; making a response rate of $96.36 \%$. The average age of women who participated is 32 years, with a minimum age of 19 years and a maximum age of 47 years. The majority of the women were married (78.3\%) and were in active employment status on their own or another's account (69.4\%). In addition, $47.6 \%$ of participants had university studies, and $90.1 \%$ of women reported that pregnancy had been sought.

The average score of depressive symptoms is 7.20 (95\% CI; 6.53-7.89). Using the cut-off point of 10 in the EPDS questionnaire, the point prevalence of depressive symptoms at 6 weeks after delivery is $26.9 \%$ (95\% CI; 21.2-33.0). The average anxiety score is 17.26 (95\% CI; 15.95-18.67). Taking the 75th percentile, the point prevalence of anxiety at 6 weeks postpartum is $27.8 \%$ (95\% CI; 21.7-34.0). Joint prevalence in our sample of comorbidity of both disorders is $20.3 \%$ (95\% CI; 15.1-25-5).

Table 1. Description of studied sample.

\begin{tabular}{|c|c|c|c|}
\hline \multicolumn{4}{|c|}{ (I) } \\
\hline Variables & $n(\%)$ & M (SD) & Median (IQR) \\
\hline Age & & $32.67(4.58)$ & \\
\hline \multicolumn{4}{|l|}{ Marital Status } \\
\hline Single & $8(3.80)$ & & \\
\hline Married & $166(78.30)$ & & \\
\hline With couple & $35(16.50)$ & & \\
\hline Separated or divorced & $3(1.40)$ & & \\
\hline \multicolumn{4}{|l|}{ Education level } \\
\hline Primary & $18(8.50)$ & & \\
\hline Secondary & $21(9.90)$ & & \\
\hline High School & $12(5.70)$ & & \\
\hline FP Middle degree & $36(17.00)$ & & \\
\hline FP Higher degree & $24(11.30)$ & & \\
\hline University & $101(47.60)$ & & \\
\hline \multicolumn{4}{|l|}{ Employment situation } \\
\hline Student & $3(1.40)$ & & \\
\hline Active or own account & $39(18.40)$ & & \\
\hline Asset & $108(50.90)$ & & \\
\hline Unemployed & $47(22.20)$ & & \\
\hline Domestic work & $15(7.10)$ & & \\
\hline \multicolumn{4}{|l|}{ Family income } \\
\hline$<$ from $500 €$ & $1(0.50)$ & & \\
\hline From 500 to $<1000 €$ & $27(12.70)$ & & \\
\hline From 1000 to $<1500 €$ & $60(28.30)$ & & \\
\hline From 1500 to $<2000 €$ & $54(25.50)$ & & \\
\hline From 2000 to $<2500 €$ & $29(13.70)$ & & \\
\hline From 2500 to $<3000 €$ & $28(13.20)$ & & \\
\hline From 3000 to $<5000 €$ & $10(4.70)$ & & \\
\hline$>$ from $5000 €$ & $3(1.40)$ & & \\
\hline \multicolumn{4}{|l|}{ Pregnancy wanted } \\
\hline Yes & $191(90.10)$ & & \\
\hline No & $21(9.90)$ & & \\
\hline Number of pregnancies & & $1.835(0.98)$ & \\
\hline \multicolumn{4}{|l|}{ Mode of delivery } \\
\hline Eutocic & $141(66.50)$ & & \\
\hline Instrumental & $32(15.10)$ & & \\
\hline Caesarean section & $39(18.40)$ & & \\
\hline \multicolumn{4}{|l|}{ Sex of newborn } \\
\hline Man & $112(52.80)$ & & \\
\hline Woman & $100(47.20)$ & & \\
\hline
\end{tabular}


Table 1. Cont.

\begin{tabular}{|c|c|c|c|}
\hline \multicolumn{4}{|c|}{ (II) } \\
\hline Variables & $n(\%)$ & M (DE) & Median (IQR) \\
\hline \multicolumn{4}{|l|}{ Family history of psychiatric pathology } \\
\hline Yes & $13(6.10)$ & & \\
\hline No & $199(93.60)$ & & \\
\hline Depressive symptoms prevalence & $57(26.90)$ & & \\
\hline Anxiety & & $17.255(10.64)$ & \\
\hline Anxiety prevalence & $59(27.80)$ & & \\
\hline $\begin{array}{l}\text { Comorbid prevalence of depressive and } \\
\text { anxiety symptoms }\end{array}$ & $43(20.30)$ & & \\
\hline Family functioning & & & $9(8.00-10.00)$ \\
\hline Social support & & & $\begin{array}{c}47.50 \\
(37.00-52.00)\end{array}$ \\
\hline Sense of coherence & & $67.066(13.50)$ & \\
\hline Self-efficacy in care & & $23.943(3.46)$ & \\
\hline Perceived burden & & $5.231(2.76)$ & \\
\hline Stressful life events & & & $\begin{array}{c}181 \\
(150.00-248.50)\end{array}$ \\
\hline Source: self-made & & & \\
\hline
\end{tabular}

\subsection{Factors Related to Depression and Anxiety}

The variables that met normal assumptions were the following: depressive symptoms, anxiety, sense of coherence, self-efficacy in care and perceived burden. The variables that did not meet normal assumptions, however, were social support, family functioning and stressful life events; therefore, Box-Cox transformations were carried out. No breaches were detected in the rest of the assumptions in regression model (e.g., Durbin-Watson of 1.94 for depressive symptoms and 2.02 for anxiety; and tolerances between 0.45 and 0.86 for depressive symptoms and between 0.45 and 0.85 for anxiety).

Regarding correlations (Table 2) a positive association was found between the presence of depressive symptoms and perceived burden $(\mathrm{r}=0.429 ; p<0.001)$ and stressful life events (rho $=0.240$; $p=0.001$ ). In addition, a negative association was found between depressive symptoms and family functioning (rho $=-0.364 ; p<0.001$ ), social support (rho $=-0.537 ; p<0.001$ ), sense of coherence $(\mathrm{r}=-0.616 ; p<0.001)$ and self-efficacy in care $(\mathrm{r}=-0.466 ; p<0.001)$. Regarding anxiety, a positive association was found with perceived burden $(\mathrm{r}=0.532 ; p=0.01)$ and stressful life events (rho $=0.186$; $p=0.001$ ). Likewise, a negative association was found between anxiety and family functioning (rho $=-0.370 ; p<0.001)$, social support (rho $=-0.539 ; p<0.001)$, sense of coherence $(\mathrm{r}=-0.644$; $p<0.001)$ and self-efficacy in care $(\mathrm{r}=-0.361 ; p<0.001)$.

In the regression model of depressive symptoms, independent variables were included together with the control variable, stressful life events. The resulting model has an $R^{2}$ of 0.52 (Table 3). In this model, the presence of depressive symptoms is positively associated with the perceived burden $(\beta=0.133 ; p=0.015)$ and negatively with self-efficacy in care $(\beta=-0.253 ; p<0.001)$, social support $(\beta=-0.334 ; p<0.001)$ and sense of coherence $(\beta=-0.231 ; p<0.001)$. No association was found with family functioning or stressful life events. Regarding the anxiety regression model, it has an $R^{2}$ of 0.58 (Table 4). In this model, anxiety is positively associated with the perceived burden $(\beta=0.273 ; p<0.001)$ and negatively with self-efficacy in care $(\beta=-0.107 ; p=0.041)$, social support $(\beta=-0.217 ; p=0.001)$ and the sense of coherence $(\beta=-0.333, p<0.001)$. No association was found with family functioning or stressful life events. 
Table 2. Correlation matrix of measures of study variables.

\begin{tabular}{|c|c|c|c|c|c|c|c|c|c|c|}
\hline Variables & 1 & 2 & 3 & 4 & 5 & 6 & 7 & 8 & 9 & 10 \\
\hline $\begin{array}{l}1 \text { Depressive } \\
\text { symptoms }\end{array}$ & 1 & & & & & & & & & \\
\hline 2 Anxiety & $0.772 * *$ & 1 & & & & & & & & \\
\hline $\begin{array}{c}3 \text { Family } \\
\text { functioning }\end{array}$ & $-0.364^{* *}$ & $-0.370 * *$ & 1 & & & & & & & \\
\hline 4 Social support & $-0.537^{* *}$ & $-0.539 * *$ & $0.570^{* *}$ & 1 & & & & & & \\
\hline $\begin{array}{l}5 \text { Sense of } \\
\text { coherence }\end{array}$ & $-0.616^{* *}$ & $-0.644^{* *}$ & $0.587^{* *}$ & $0.689^{* *}$ & 1 & & & & & \\
\hline $\begin{array}{c}6 \text { Self-efficacy } \\
\text { in care }\end{array}$ & $-0.466 * *$ & $-0.361 * *$ & $0.152 *$ & 0.273 ** & $0.376^{* *}$ & 1 & & & & \\
\hline $\begin{array}{l}7 \text { Perceived } \\
\text { burden }\end{array}$ & $0.429^{* *}$ & 0.532 ** & $-0.314^{* *}$ & $-0.379 * *$ & $-0.447^{* *}$ & $-0.258^{* *}$ & 1 & & & \\
\hline $\begin{array}{c}8 \text { Stressful life } \\
\text { events }\end{array}$ & 0.240 ** & $0.186^{* *}$ & $-0.260^{* *}$ & -0.236 ** & $-0.305^{* *}$ & -0.050 & 0.211 ** & 1 & & \\
\hline 9 Age & 0.032 & 0.101 & -0.019 & -0.052 & -0.035 & -0.107 & 0.075 & -0.109 & 1 & \\
\hline $\begin{array}{l}10 \text { Number of } \\
\text { pregnancies }\end{array}$ & 0.075 & 0.097 & 0.005 & -0.102 & -0.072 & 0.017 & 0.033 & -0.010 & $0.318^{* *}$ & 1 \\
\hline
\end{tabular}

${ }^{* *}$ Correlation is significant at 0.01 level; ${ }^{*}$ correlation is significant at 0.05 level; source: self made.

Table 3. Multiple linear regression by steps (dependent variable: depressive symptoms).

\begin{tabular}{ccccc}
\hline Variables & Beta & Standard Error & Beta Standardised & $p$ \\
\hline Perceived burden & 0.230 & 0.094 & 0.133 & 0.015 \\
Self-efficacy in care & -0.348 & 0.072 & -0.253 & $<0.001$ \\
Social support & -0.161 & 0.032 & -0.334 & $<0.001$ \\
Sense of coherence & -0.081 & 0.025 & -0.231 & 0.001 \\
\hline
\end{tabular}

$$
R^{2}: 0.52 \text {; source: self made. }
$$

Table 4. Multiple linear regression by steps (dependent variable: anxiety).

\begin{tabular}{ccccc}
\hline Variables & Beta & Standard Error & Beta Standardised & $p$ \\
\hline Perceived burden & 1.052 & 0.209 & 0.273 & $<0.001$ \\
Self-efficacy in care & -0.329 & 0.160 & -0.107 & 0.041 \\
Social support & -0.234 & 0.072 & -0.217 & 0.001 \\
Sense of coherence & -0.262 & 0.056 & -0.333 & $<0.001$ \\
\hline
\end{tabular}

$R^{2}: 0.58$; source: self made.

\section{Discussion}

In this study, approximately one in four women had depressive symptoms at 6 weeks postpartum - the proportion of anxiety being similar. These figures show the importance of these problems, which are higher than those found in other periods outside the puerperium [1,12,21,28,62]. The results are superior to those of other studies in the postpartum period $[20,63,64]$. The differences could be due to the fact that the questionnaires used are screening tools, so they can overestimate the presence of the disorders [65], the cut-off point used in the questionnaires [65] or even the moment at which the prevalence is measured (the figures decrease as the postpartum) [66].

In this study, the authors found that less perceived social support, greater perceived burden, less self-efficacy in care and a lesser sense of coherence are accompanied by increased depressive symptoms and anxiety in women in the puerperium (i.e., at 6 weeks after delivery), regardless of the presence of other stressful life events unrelated to the care of the newborn.

Our results are consistent with those of other studies that have analysed the relationship between anxiety, depression and social support in postpartum women [41,67-70], self-efficacy in care [42,71,72] and sense of coherence $[40,73,74]$. The authors have not found studies that relate anxiety and depression to perceived burden, although there are studies that relate the above problems to perceived stress in 
relation to newborn care $[43,75,76]$, where they show a directly proportional relationship. Perceived burden can be considered as the assessment of the care situation as stressful [77].

The findings of this study improve the available evidence on the possible risk factor role of perceived burden on anxiety and depression in the puerperium and the possible protective effect of perceived social support, self-efficacy in care and the sense of coherence. This is because in this study the effect of these factors was analysed together, controlling for possible confounding factors and with a sufficient sample size and extracted by probabilistic sampling, with a very low percentage of refusal to participate in the study. In addition, this study highlights the important contribution of the above factors in explaining the variance of depressive symptoms and anxiety.

According to Lazarus and Folkman [78], the proliferation of stress towards its negative emotional consequences, among which are anxiety and depression, occurs when assessing potentially stressful situations as a threat to which the person cannot respond. The data support the hypothesis that those women who perceive as adequate or satisfactory the support they receive from family and friends in the care of the newborn, perceive their capacities regarding such care as adequate, and have a greater sense of coherence, so they see the care situation as understandable (i.e., internal and external stimuli are perceived as ordered, structured and rationally understandable), manageable (i.e., they believe they have the necessary resources to cope with it) and significant (i.e., they feel it is worth dedicating efforts to it), valuing the care situation as less stressful, in line with the theoretical approaches of Cohen et al. [79] for social support, Bandura [80] for self-efficacy and Antonovsky [36] for the sense of coherence. On the other hand, our results support the hypothesis that those women who perceive a higher level of perceived burden in the realisation of care related to the newborn, could feel overcome by the care situation, trapped by it and excluded from their social relationships and that this perception can make them perceive the care situation as more stressful [77].

The findings of this study allow us to propose a risk profile of anxiety and depression in the puerperium that would be characterised by low perceived social support, high perceived burden, low self-efficacy in care and low sense of coherence. This risk profile could be useful for screening and early detection of women at high risk of anxiety and depression. On the other hand, the results justify assessing the feasibility of interventions aimed at improving the perception of competence in care [81], to work on the sensation of feeling connected as a way to improve the perception of social support received [82], to promote the sense of coherence [39] and to alleviate the feeling of burden in care by fostering a positive perception of the newborn rearing [83].

\section{Limitations}

The study has some limitations that should be noted. Firstly, it is a cross-sectional, descriptive study of correlation, so it can only describe the associations between the study factors, and the causality between them cannot be deduced. In addition, because of the foregoing and with regard to the determination of prevalence, we lack information on whether the prevalence found vary when approaching or moving away at the time of delivery. Secondly, the questionnaires used are screening tools, so they can overestimate the prevalence of anxiety and depression. This is the reason why, in this study, the authors talk about depressive symptoms and anxiety and not depression and anxiety, respectively.

\section{Conclusions}

Despite the above limitations, we can reach the following conclusions: (1) depressive and anxiety symptoms in the puerperium period may be more prevalent than in other periods of a woman's life; (2) perceived social support, self-efficacy in caring for the newborn and sense of coherence can be protective factors for depressive symptoms and anxiety in the puerperium; (3) perceived burden in caring for the newborn may be a risk factor for the mentioned symptoms.

At the level of clinical practice, screening for the above factors may be justified for early prevention of depressive and anxiety disorders in the postpartum period. 
Author Contributions: Conceptualization, D.F.-A.; A.F.-O., and R.d.-P.-C.; methodology, D.F.-A.; A.F.-O., and R.d.-P.-C.; formal analysis, D.F.-A., and R.d.-P.-C.; investigation, D.F.-A., and A.F.-O.; resources, D.F.-A.;data curation, D.F.-A.; A.F.-O., and R.d.-P.-C.; writing—original draft preparation, D.F.-A.; writing—review and editing, D.F.-A.; A.F.-O., and R.d.-P.-C.; visualization, D.F.-A.; supervision, R.d.-P.-C. All authors have read and agreed to the published version of the manuscript.

Funding: This research received no external funding.

Conflicts of Interest: The authors declare no conflict of interest.

\section{References}

1. Leahy-Warren, P.; McCarthy, G.; Corcoran, P. Postnatal depression in first-time mothers: Prevalence and relationships between functional and structural social support at 6 and 12 weeks postpartum. Arch. Psychiatr. Nurs. 2011, 25, 174-184. [CrossRef] [PubMed]

2. Mercer, R.T. Becoming a mother versus maternal role attainment. J. Nurs. Scholarsh. 2004, 36, $226-232$. [CrossRef] [PubMed]

3. Hill, P.D.; Aldag, J.C. Maternal perceived quality of life following childbirth. J. Obstet. Gynecol. Neonatal Nurs. 2007, 36, 328-334. [CrossRef]

4. Rallis, S.; Skouteris, H.; Wertheim, E.H.; Paxton, S.J. Predictors of body image during the first year postpartum: A prospective study. Women Health 2007, 45, 87-104. [CrossRef] [PubMed]

5. Britton, J.R. Maternal anxiety: Course and antecedents during the early postpartum period. Depress. Anxiety 2008, 25, 793-800. [CrossRef] [PubMed]

6. World Health Organization. Depression. Available online: http://www.who.int/mediacentre/factsheets/fs369/ es/ (accessed on 16 February 2020).

7. Kessler, R.C.; Berglund, P.; Demler, O.; Jin, R.; Merikangas, K.R.; Walters, E.E. Lifetime prevalence and age-of-onset distributions of DSM-IV disorders in the National Comorbidity Survey Replication. Arch. Gen. Psychiatry 2005, 62, 593-602. [CrossRef]

8. Association, A.P. Diagnostic and Statistical Manual of Mental Disorders DSM-V; APA: Washington, DC, USA, 2013.

9. O'Hara, M.W.; Wisner, K.L. Perinatal mental illness: Definition, description and aetiology. Best Pract. Res. Clin. Obstet. Gynaecol. 2014, 28, 3-12. [CrossRef]

10. Cohen, L.S.; Wang, B.; Nonacs, R.; Viguera, A.C.; Lemon, E.L.; Freeman, M.P. Treatment of mood disorders during pregnancy and postpartum. Psychiatr. Clin. N. Am. 2010, 33, 273-293. [CrossRef]

11. Fiala, A.; Švancara, J.; Klánová, J.; Kašpárek, T. Sociodemographic and delivery risk factors for developing postpartum depression in a sample of 3233 mothers from the Czech ELSPAC study. BMC Psychiatry 2017, 17, 104. [CrossRef]

12. Gaynes, B.N.; Gavin, N.; Meltzer-Brody, S.; Lohr, K.N.; Swinson, T.; Gartlehner, G.; Brody, S.; Miller, W.C. Perinatal depression: Prevalence, screening accuracy, and screening outcomes. Evid. Rep./Technol. Assess. 2005, 119, 1-8. [CrossRef]

13. Escribà-Agüir, V.; Artazcoz, L. Gender differences in postpartum depression: A longitudinal cohort study. J. Epidemiol. Community Health 2011, 65, 320-326. [CrossRef]

14. Garcia-Esteve, L.; Ascaso, C.; Ojuel, J.; Navarro, P. Validation of the Edinburgh Postnatal Depression Scale (EPDS) in Spanish mothers. J. Affect. Disord. 2003, 75, 71-76. [CrossRef]

15. McMahon, C.A.; Barnett, B.; Kowalenko, N.M.; Tennant, C.C. Maternal attachment state of mind moderates the impact of postnatal depression on infant attachment. J. Child. Psychol. Psychiatry Allied Discip. 2006, 47, 660-669. [CrossRef]

16. Giallo, R.; Cooklin, A.; Nicholson, J.M. Risk factors associated with trajectories of mothers' depressive symptoms across the early parenting period: An Australian population-based longitudinal study. Arch. Women's Ment. Health 2014, 17, 115-125. [CrossRef] [PubMed]

17. Grace, S.L.; Evindar, A.; Stewart, D.E. The effect of postpartum depression on child cognitive development and behavior: A review and critical analysis of the literature. Arch. Women's Ment. Health 2003, 6, 263-274. [CrossRef] [PubMed]

18. Norhayati, M.N.; Hazlina, N.H.; Asrenee, A.R.; Emilin, W.M. Magnitude and risk factors for postpartum symptoms: A literature review. J. Affect. Disord. 2015, 175, 34-52. [CrossRef] [PubMed] 
19. Bener, A.; Gerber, L.M.; Sheikh, J. Prevalence of psychiatric disorders and associated risk factors in women during their postpartum period: A major public health problem and global comparison. Int. J. Women's Health 2012, 4, 191-200. [CrossRef]

20. Falah-Hassani, K.; Shiri, R.; Dennis, C.L. Prevalence and risk factors for comorbid postpartum depressive symptomatology and anxiety. J. Affect. Disord. 2016, 198, 142-147. [CrossRef]

21. Dennis, C.L.; Falah-Hassani, K.; Shiri, R. Prevalence of antenatal and postnatal anxiety: Systematic review and meta-analysis. Br. J. Psychiatry 2017, 210, 315-323. [CrossRef]

22. Clout, D.; Brown, R. Sociodemographic, pregnancy, obstetric, and postnatal predictors of postpartum stress, anxiety and depression in new mothers. J. Affect. Disord. 2015, 188, 60-67. [CrossRef]

23. Porter, C.L.; Hsu, H.C. First-time mothers' perceptions of efficacy during the transition to motherhood: Links to infant temperament. J. Fam. Psychol. 2003, 17, 54-64. [CrossRef]

24. Fahey, J.O.; Shenassa, E. Understanding and meeting the needs of women in the postpartum period: The Perinatal Maternal Health Promotion Model. J. Midwifery Women's Health 2013, 58, 613-621. [CrossRef]

25. Cheng, C.Y.; Walker, L.O.; Chu, T.P. Physical conditions and depressive symptoms of Chinese postpartum mothers in the United States and Taiwan. Health Care Women Int. 2013, 34, 539-555. [CrossRef] [PubMed]

26. Robertson, E.; Grace, S.; Wallington, T.; Stewart, D.E. Antenatal risk factors for postpartum depression: A synthesis of recent literature. Gen. Hosp. Psychiatry 2004, 26, 289-295. [CrossRef] [PubMed]

27. Salm Ward, T.; Kanu, F.A.; Robb, S.W. Prevalence of stressful life events during pregnancy and its association with postpartum depressive symptoms. Arch. Women's Ment. Health 2017, 20, 161-171. [CrossRef] [PubMed]

28. Hahn-Holbrook, J.; Haselton, M.G.; Dunkel Schetter, C.; Glynn, L.M. Does breastfeeding offer protection against maternal depressive symptomatology? Arch. Women's Ment. Health 2013, 16, 411-422. [CrossRef] [PubMed]

29. Sword, W.; Landy, C.K.; Thabane, L.; Watt, S.; Krueger, P.; Farine, D.; Foster, G. Is mode of delivery associated with postpartum depression at 6 weeks: A prospective cohort study. BJOG 2011, 118, 966-977. [CrossRef]

30. Reck, C.; Van Den Bergh, B.; Tietz, A.; Müller, M.; Ropeter, A.; Zipser, B.; Pauen, S. Maternal avoidance, anxiety cognitions and interactive behaviour predicts infant development at 12 months in the context of anxiety disorders in the postpartum period. Infant Behav. Dev. 2018, 50, 116-131. [CrossRef]

31. Feldman, R.; Granat, A.; Pariente, C.; Kanety, H.; Kuint, J.; Gilboa-Schechtman, E. Maternal depression and anxiety across the postpartum year and infant social engagement, fear regulation, and stress reactivity. J. Am. Acad. Child. Adolesc. Psychiatry 2009, 48, 919-927. [CrossRef]

32. Warfa, N.; Harper, M.; Nicolais, G.; Bhui, K. Adult attachment style as a risk factor for maternal postnatal depression: A systematic review. BMC Psychol. 2014, 2, 56. [CrossRef]

33. Broadhead, W.E.; Gehlbach, S.H.; de Gruy, F.V.; Kaplan, B.H. The Duke-UNC Functional Social Support Questionnaire. Measurement of social support in family medicine patients. Med. Care 1988, 26, 709-723. [CrossRef] [PubMed]

34. Smilkenstein, G. The family APGAR: A proposal multidimensional health locus control (MHCL) scales. Health Educ. Monograf. 1978, 6, 160-170.

35. Lawton, M.P.; Moss, M.; Hoffman, C.; Perkinson, M. Two transitions in daughters' caregiving careers. Gerontologist 2000, 40, 437-448. [CrossRef] [PubMed]

36. Antonovsky, A. The structure and properties of the sense of coherence scale. Soc. Sci. Med. 1993, 36, 725-733. [CrossRef]

37. Crespo, M.; Martínez, J.L. El Estrés en Cuidadores de Mayores Dependientes: Cuidarse Para Cuidar; Psicología Pirámide: Madrid, Spain, 2007.

38. Del-Pino-Casado, R.; Rodríguez Cardosa, M.; López-Martínez, C.; Orgeta, V. The association between subjective caregiver burden and depressive symptoms in carers of older relatives: A systematic review and meta-analysis. PLoS ONE 2019, 14, e0217648. [CrossRef] [PubMed]

39. Del-Pino-Casado, R.; Espinosa, A.; López, C.; Orgeta, V. Sense of coherence, burden and mental health in caregiving: A systematic review and meta-analysis. J. Affect. Disord. 2019, 242, 14-21. [CrossRef]

40. Ferguson, S.; Browne, J.; Taylor, J.; Davis, D. Sense of coherence and women's birthing outcomes: A longitudinal survey. Midwifery 2016, 34, 158-165. [CrossRef]

41. Reid, K.M.; Taylor, M.G. Social support, stress, and maternal postpartum depression: A comparison of supportive relationships. Soc. Sci. Res. 2015, 54, 246-262. [CrossRef] 
42. Wernand, J.J.; Kunseler, F.C.; Oosterman, M.; Beekman, A.T.; Schuengel, C. Prenatal changes in parenting self-efficacy: Linkages with anxiety and depressive symptoms in primiparous women. Infant Ment. Health J. 2014, 35, 42-50. [CrossRef]

43. Leung, S.S.; Martinson, I.M.; Arthur, D. Postpartum depression and related psychosocial variables in Hong Kong Chinese women: Findings from a prospective study. Res. Nurs. Health 2005, 28, 27-38. [CrossRef]

44. Gan, Y.; Xiong, R.; Song, J.; Xiong, X.; Yu, F.; Gao, W.; Hu, H.; Zhang, J.; Tian, Y.; Gu, X.; et al. The effect of perceived social support during early pregnancy on depressive symptoms at 6 weeks postpartum: A prospective study. BMC Psychiatry 2019, 19, 232. [CrossRef]

45. Abadiga, M. Magnitude and associated factors of postpartum depression among women in Nekemte town, East Wollega zone, west Ethiopia, 2019: A community-based study. PLoS ONE 2019, 14, e0224792. [CrossRef] [PubMed]

46. Alzahrani, A.D. Risk Factors for Postnatal Depression among Primipara Mothers. Span. J. Psychol. 2019, 22, E35. [CrossRef]

47. Mohammad, K.I.; Gamble, J.; Creedy, D.K. Prevalence and factors associated with the development of antenatal and postnatal depression among Jordanian women. Midwifery 2011, 27, e238-e245. [CrossRef] [PubMed]

48. Hassert, S.; Sharon, S.R.; Payakkakom, A.; Kodyšová, E. Postpartum Depressive Symptoms: Risks for Czech and Thai Mothers. J. Perinat. Educ. 2018, 27,38-49. [CrossRef]

49. Machin, D.; Campbell, M.J.; Fayers, P.M.; Pinol, A.P. Sample Size Tables For Clinical Studies, 2nd ed.; Blackwell Science Ltd.: Oxford, UK, 1997; pp. 153-157.

50. Bellón Saameño, J.; Delgado Sánchez, A.; Luna del Castillo, J.; Lardelli Claret, P. Validez y fiabilidad del cuestionario de apoyo social funcional Duke-UNC-11. Aten. Primaria 1996, 18, 153-163. [PubMed]

51. Bellón Saameño, J.; Delgado Sánchez, A.; Luna del Castillo, J.; Lardelli Claret, P. Validez y fiabilidad del cuestionario de función familiar Apgar-familiar. Aten. Primaria 1996, 18, 289-296. [PubMed]

52. Virués-Ortega, J.; Martínez-Martín, P.; Del Barrio, J.L.; Lozano, L.M. Validación transcultural de la Escala de Sentido de Coherencia de Antonovsky (OLQ-13) en ancianos mayores de 70 años. Med. Clin. 2007, 128, 486-492. [CrossRef] [PubMed]

53. Robinson, B.C. Validation of a Caregiver Strain Index. J. Gerontol. 1983, 38, 344-348. [CrossRef] [PubMed]

54. Alonso, S.L.; Serrano, M.M. Validación del Índice de Esfuerzo del Cuidador en la población española. Enferm. Comun. 2005, 1, 12-17.

55. Cox, J.L.; Holden, J.M.; Sagovsky, R. Detection of postnatal depression. Development of the 10-item Edinburgh Postnatal Depression Scale. Br. J. Psychiatry 1987, 150, 782-786. [CrossRef] [PubMed]

56. Ministry of Health, Social Services and Equality. Clinical Practice Guide for Pregnancy and Puerperium Care; Ministry of Health, Social Services and Equality: Madrid, Spain, 2014.

57. Spielberger, R.L.; Lushene, R. Manual del Cuestionario de Ansiedad Estado/Rasgo (STAI); TEA Ediciones: Madrid, Spain, 1982.

58. Guillén-Riquelme, A.; Buela-Casal, G. Actualización psicométrica y funcionamiento diferencial de los ítems en el State Trait Anxiety Inventory (STAI). Psicothema 2011, 23, 510-515. [PubMed]

59. Holmes, T.H.; Rahe, R.H. The Social Readjustment Rating Scale. J. Psychosom. Res. 1967, 11, $213-218$. [CrossRef]

60. De Rivera, G.; Revuelta, J.; Morera Fumero, A. La valoración de sucesos vitales: Adaptación española de la escala de Holmes y Rahe. Psiquis 1983, 4, 7-11.

61. Box, G.E.; Cox, D.R. An analysis of transformations. J. R. Stat. Soc. Ser. B (Methodol.) 1964, 26, $211-243$. [CrossRef]

62. Ghaedrahmati, M.; Kazemi, A.; Kheirabadi, G.; Bahrami, M.; Ebrahimi, A. Examining the relationship between mothers' prenatal mental health and demographic factors with postpartum depression. J. Educ. Health Promot. 2018, 7, 146. [CrossRef] [PubMed]

63. Razurel, C.; Kaiser, B.; Antonietti, J.P.; Epiney, M.; Sellenet, C. Relationship between perceived perinatal stress and depressive symptoms, anxiety, and parental self-efficacy in primiparous mothers and the role of social support. Women Health 2017, 57, 154-172. [CrossRef]

64. Underwood, L.; Waldie, K.; D'Souza, S.; Peterson, E.R.; Morton, S. A review of longitudinal studies on antenatal and postnatal depression. Arch. Women's Ment. Health 2016, 19, 711-720. [CrossRef] 
65. Thombs, B.D.; Kwakkenbos, L.; Levis, A.W.; Benedetti, A. Addressing overestimation of the prevalence of depression based on self-report screening questionnaires. CMAJ 2018, 190, E44-E49. [CrossRef]

66. Petrozzi, A.; Gagliardi, L. Anxious and depressive components of Edinburgh Postnatal Depression Scale in maternal postpartum psychological problems. J. Perinat. Med. 2013, 41, 343-348. [CrossRef] [PubMed]

67. Zheng, X.; Morrell, J.; Watts, K. Changes in maternal self-efficacy, postnatal depression symptoms and social support among Chinese primiparous women during the initial postpartum period: A longitudinal study. Midwifery 2018, 62, 151-160. [CrossRef] [PubMed]

68. Aktan, N.M. Social support and anxiety in pregnant and postpartum women: A secondary analysis. Clin. Nurs. Res. 2012, 21, 183-194. [CrossRef] [PubMed]

69. Eastwood, J.G.; Jalaludin, B.B.; Kemp, L.A.; Phung, H.N.; Barnett, B.E. Relationship of postnatal depressive symptoms to infant temperament, maternal expectations, social support and other potential risk factors: Findings from a large Australian cross-sectional study. BMC Pregnancy Childbirth 2012, 12, 148. [CrossRef]

70. Navarrete, L.E.; Lara-Cantú, M.A.; Navarro, C.; Gómez, M.E.; Morales, F. Psychosocial factors predicting postnatal anxiety symptoms and their relation to symptoms of postpartum depression. Rev. Investig. Clin. 2012, 64, 625-633.

71. Abdollahi, F.; Agajani-Delavar, M.; Zarghami, M.; Lye, M.S. Postpartum Mental Health in First-Time Mothers: A Cohort Study. Iran. J. Psychiatry Behav. Sci. 2016, 10, e426. [CrossRef]

72. Leahy-Warren, P.; McCarthy, G. Maternal parental self-efficacy in the postpartum period. Midwifery 2011, 27, 802-810. [CrossRef] [PubMed]

73. Sjöström, H.; Langius-Eklöf, A.; Hjertberg, R. Well-being and sense of coherence during pregnancy. Acta Obstet. Gynecol. Scand. 2004, 83, 1112-1118. [CrossRef]

74. Weidner, K.; Bittner, A.; Pirling, S.; Galle, M.; Junge-Hoffmeister, J.; Einsle, F.; Stöbel-Richter, Y. Protective factors for postpartum depression. Z. Psychosom. Med. Psychother. 2013, 59, 391-407.

75. Dennis, C.L.; Falah-Hassani, K.; Brown, H.K.; Vigod, S.N. Identifying women at risk for postpartum anxiety: A prospective population-based study. Acta Psychiatr. Scand. 2016, 134, 485-493. [CrossRef]

76. Nurbaeti, I.; Deoisres, W.; Hengudomsub, P. Association between psychosocial factors and postpartum depression in South Jakarta, Indonesia. Sex. Reprod. Healthc. 2019, 20, 72-76. [CrossRef]

77. Del-Pino-Casado, R.; Palomino-Moral, P.A.; Pastor-Bravo, M.D.M. Determinants of depression in primary caregivers of disabled older relatives: A path analysis. BMC Geriatr. 2017, 17, 274. [CrossRef] [PubMed]

78. Folkman, S.; Lazarus, R.S. Stress, Appraisal, and Coping; Springer Publishing Company: New York, NY, USA, 1984.

79. Cohen, S.; Gottlieb, B.H.; Underwood, L.G. Social relationships and health. In Social Support Measurement and Intervention: A Guide for Health and Social Scientists; Cohen, S., Gottlieb, B.H., Underwood, L.G., Eds.; Oxford University Press: New York, NY, USA, 2000; pp. 3-25.

80. Bandura, A. Social Foundations of Thought and an Action: A Social Cognitive Approach; Prentice-Hall: Englewood Cliffs, NJ, USA, 1986.

81. Tang, W.K.; Chan, C.Y. Effects of psychosocial interventions on self-efficacy of dementia caregivers: A literature review. Int. J. Geriatr. Psychiatry 2016, 31, 475-493. [CrossRef] [PubMed]

82. Elvish, R.; Lever, S.-J.; Johnstone, J.; Cawley, R.; Keady, J. Psychological interventions for carers of people with dementia: A systematic review of quantitative and qualitative evidence. Couns. Psychother. Res. 2013, 13, 106-125. [CrossRef]

83. Taheri, M.; Takian, A.; Taghizadeh, Z.; Jafari, N.; Sarafraz, N. Creating a positive perception of childbirth experience: Systematic review and meta-analysis of prenatal and intrapartum interventions. Reprod. Health 2018, 15, 73. [CrossRef]

(C) 2020 by the authors. Licensee MDPI, Basel, Switzerland. This article is an open access article distributed under the terms and conditions of the Creative Commons Attribution (CC BY) license (http://creativecommons.org/licenses/by/4.0/). 